osteoarthritis using knee joint distraction, Annals of the rheumatic diseases 75(5) (2016) 908-15

[2] A. Altaie, T.G. Baboolal, O. Wall, E. Jones, D. McGonagle, Platelet lysate enhances synovial fluid multipotential stromal cells functions: Implications for therapeutic use, Cytotherapy 20(3) (2018) 375-384.

Disclosure of Interests: Ala Altaie: None declared, Elena Jones: None declared, Owen Wall: None declared, Dennis McGonagle Grant/research support from: Janssen Research \& Development, LLC

DOI: 10.1136/annrheumdis-2020-eular.5717

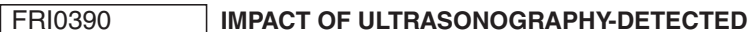 QUADRICEPS CALCIFIC TENDONITIS ON PAIN AND FUNCTION IN PATIENTS WITH PRIMARY KNEE OSTEOARTHRITIS}

M. A. Mortada ${ }^{1}$, Y. A. Amer ${ }^{1} .{ }^{1}$ Zagazig University - Faculty of Medicine, Rheumatology, Zagazig, Egypt

Background: Calcific tendonitis is most commonly seen around shoulder joint. Few cases of quadriceps calcific tendonitis (QCT) of were reported. Routine use of ultrasonography in diagnosis of knee osteoarthritis has resulted in detection of many cases of QCT.

Up to the best of our knowledge, this is the first study to detect impact of QCT in knee osteoarthritis by ultrasonography.

Objectives: To compare pain, function, and clinical and radiological findings among primary KOA patients with or without ultrasonography-detected QCT.

Methods: A prospective, observational study study was conducted on 214 patients with knee OA in the period between february 2019 to july 2019 . Ultrasonography of knee joints was done according to EULAR guidelines. Quadriceps calcific tendonitis is defined as hyperechoic mass within the quadriceps tendon with posterior shadowing. The patients were categorized into two groups according to the presence or absence of QCT.

Radiological grades of Kellgren-Lawrence were recorded. Pain and functional status was assessed by visual analog scale (VAS), Health Assessment Questionnaire-II (HAQ-II), and Western Ontario and McMaster Universities Osteoarthritis Index (WOMAC)

Results: QCT were detected in 25 (11.6\%) patients. Most cases of QCT were detected in vastus lateralis $18(72 \%)$, then in vastus intermedius $5(20 \%)$ and only 2 cases were detected in vastus medialis.

QCT were detected mainly in advanced stages of knee OA; 22 cases of QCT were found in patients with grade $4 \mathrm{KOA}$.

The presence of QCT was statistically significant related $\left(P<0.05^{*}\right)$ with age, VAS, HAQ-II, WOMAC subscales, synovitis and effusion.

Conclusion: Quadriceps calcific tendonitis is not rare. Ultrasonography can detect QCT in many cases with advanced knee OA. QCT is associated with increased pain and dysfunction in knee OA

References: None

Disclosure of Interests: None declared

DOI: 10.1136/annrheumdis-2020-eular.5095

\section{FRI0391 METABOLIC FACTORS ASSOCIATED TO RADIOGRAPHIC KNEE OSTEOARTHRITIS IN INDIVIDUALS WITH KNEE PAIN}

M. Andersson ${ }^{1,2}$, E. Haglund ${ }^{2,3,4}$, K. Aili ${ }^{2,5}$, A. Bremander ${ }^{2,6,7}$, F. Kindberg ${ }^{2}$, S. Bergman ${ }^{2,8,9}$. ' Lund University, Department of Clinical Sciences, Rheumatology, Lund, Sweden; ${ }^{2}$ Spenshult Research and Development Centre, Halmstad, Sweden; ${ }^{3}$ Lund University, Department of Clinical Sciences, Rheumatology, Lund, Sweden; ${ }^{4}$ Halmstad University, School of Business, Engineering and Science, Halmstad, Sweden; ${ }^{5}$ Halmstad University, School of Health and Welfare, Halmstad, Sweden; ${ }^{6}$ Lund University, Department of Clinical Sciences, Rheumatology, Lund, Sweden; ${ }^{7}$ University of Southern Denmark, Department of Regional Health Research, Odense, Denmark; ${ }^{8}$ Lund University, Department of Clinical Sciences, Rheumatology, Lund, Sweden; ${ }^{9}$ The Sahlgrenska Academy, University of Gothenburg, Primary Health Care Unit, Department of Public Health and Community Medicine, Gothenburg, Sweden

Background: Metabolic factors have been shown to be associated to radiographic knee osteoarthritis (OA) [1]. More knowledge about associations between metabolic factors and early clinical knee OA is needed.

Objectives: The aim was to study associations between metabolic factors and radiographic knee $O A$ in individuals with knee pain

Methods: In total 272 individuals with radiographs at baseline, from an ongoing longitudinal study of knee pain (without cruciate ligament injury), were included in the present cross-sectional study. At baseline BMI, waist circumference (WC) and visceral fat area (VFA) were assessed. Fasting plasma glucose, triglycerides, cholesterol, HDL-and LDL-cholesterol were analysed. Metabolic syndrome (MetS) was present if central obesity (WC $\geq 94 \mathrm{~cm}$ in men and $\geq 80 \mathrm{~cm}$ in women) plus any two of the following factors: raised blood pressure (systolic blood pressure $\geq 130$ or diastolic blood pressure $\geq 85 \mathrm{~mm} \mathrm{Hg}$ or treatment of hypertension), raised triglycerides ( $\geq 1.7 \mathrm{mmol} / \mathrm{L}$ or specific treatment), reduced HDL-choles terol (men $<1.03 \mathrm{mmol} / \mathrm{L}$ and women $<1.29 \mathrm{mmol} / \mathrm{L}$ or specific treatment), raised glucose (glucose $\geq 5.6 \mathrm{mmol} / \mathrm{L}$, or type 2 diabetes)

The individuals were divided in two groups according to Ahlbäck [2], one group, who had grade I or more in at least one knee (radiographic knee OA, ROA) $n=62$ and the other group, not fulfilling Ahlbäck criteria (no radiograhic knee OA, No OA) $n=211$. The associations between metabolic factors and knee OA were calculated by crude logistic regression analyses, adjusting for age and sex.

Results: The group with radiographic knee OA were older, had higher BMI higher amount of visceral fat and more had central obesity, table 1. Ninety- four percent of the group with ROA had central obesity compared to $76 \%, p=0.002$ in the no OA group. There was no difference between the groups regarding MetS $44 \%$ in the ROA group vs. $39 \%, p=0.5$. The group with ROA had increased cholesterol, triglycerides and LDL-cholesterol. There were no differences in fasting glucose between the groups, though both groups had a mean glucose value in the upper range of normal value, table 1. Factors associated to having radiographic knee OA were age (OR 1.11, 95\% Cl 1.06-1.17), BMI (1.07, 1.003-1.13), central obesity $(3.91,1.32-11.61)$ and raised triglycerides $(2.35,1.03-5.38)$

Table 1. Baseline descriptives

\begin{tabular}{|c|c|c|c|}
\hline & $\begin{array}{c}\text { No OA } \\
\text { Mean (sd) }\end{array}$ & $\begin{array}{c}\text { ROA } \\
\text { Mean(sd) }\end{array}$ & $\mathrm{p}$-value \\
\hline $\mathrm{N}$ & 211 & 62 & \\
\hline Age & $50(9)$ & $56(4)$ & $<0.001$ \\
\hline Sex, women, \% & 66 & 71 & 0.454 \\
\hline BMI & $25.9(4.7)$ & $27.7(4.7)$ & 0.007 \\
\hline VFA $\left(\mathrm{cm}^{2}\right)$ & $109(53)$ & $126(52)$ & 0.026 \\
\hline WC, $\mathrm{cm}$ & $94(13)$ & $99(13)$ & 0.006 \\
\hline Raised Blood pressure, \% & 66 & 53 & 0.063 \\
\hline Cholesterol (mmol/L) & $5.2(1.0)$ & $5.5(1.1)$ & 0.033 \\
\hline Triglycerides (mmol/L) & $1.0(0.6)$ & $1.2(0.7)$ & 0.035 \\
\hline Raised triglycerides, \% & 9 & 21 & 0.008 \\
\hline LDL-cholesterol (mmol/L) & $3.4(1.0)$ & $3.7(1.1)$ & 0.027 \\
\hline HDL-cholesterol (mmol/L) & $1.7(0.4)$ & $1.7(0.5)$ & 0.547 \\
\hline Reduced HDL & 11 & 15 & 0.460 \\
\hline Glucose $(\mathrm{mmol} / \mathrm{L})$ & $5.5(0.9)$ & $5.5(0.5)$ & 0.858 \\
\hline
\end{tabular}

Conclusion: There were associations between some metabolic factors and radiographic knee OA in individuals with knee pain. Fasting glucose was increased in both groups. The associations between metabolic risk factors and the development of knee OA needs to be assessed in longitudinal studies.

References:

[1] Sellam J, Bone Spine 2013;80:568-73.

[2] Ahlback S,. Acta Radiol Diagn (Stockh) 1968Suppl 277:7-72.

Disclosure of Interests: None declared

DOI: 10.1136/annrheumdis-2020-eular.2114

\section{\begin{tabular}{|l|l}
\hline FRI0392 ADVERSE EVENTS IN PATIENTS WITH \\
\hline
\end{tabular} OSTEOARTHRITIS TREATED WITH SUBCUTANEOUS TANEZUMAB: A POOLED ANALYSIS OF THE OVERALL POPULATION AND SELECTED SUBGROUPS FROM 3 RANDOMISED PLACEBO-CONTROLLED TRIALS}

F. Berenbaum ${ }^{1}$, A. Kivitz ${ }^{2}$, T. Schnitzer ${ }^{3}$, M. Brown ${ }^{4}$, S. Donevan ${ }^{5}$, A. Hickman ${ }^{4}$, L. Viktrup ${ }^{6}$, C. West ${ }^{4}$, T. Yamabe ${ }^{4} .{ }^{1}$ Sorbonne Université, INSERM, AP-HP Hospital Saint Antoine, Paris, France; ${ }^{2}$ Altoona Center for Clinical Research, Duncansville, United States of America; ${ }^{3}$ Northwestern University Feinberg School of Medicine, Chicago, United States of America; ${ }^{4}$ Pfizer Inc., Groton, United States of America; ${ }^{5}$ Pfizer Inc., New York, United States of America; ${ }^{6}$ Eli Lilly and Co., Indianapolis, United States of America

Background: Tanezumab, a monoclonal antibody against nerve growth factor (NGF), is in development for the treatment of osteoarthritis (OA).

Objectives: To assess the effects of gender, age and body mass index (BMI) on the incidence of adverse events (AEs) in patients ( $p$ ts) treated with subcutaneous (SC) tanezumab in pooled data from three phase 3 OA studies. Anti-NGF therapy has been associated with joint safety events ${ }^{1}$. Here we focus on treatment emergent AEs, including abnormalities of peripheral sensation (APS).

Methods: All three randomised, double-blind, placebo-controlled studies enrolled pts with radiographically-confirmed OA of the hip or knee, who had inadequate response or could not tolerate standard of care analgesics. In the 16-week (wk) Study 1 (NCT01089725), pts received placebo, tanezumab $2.5 \mathrm{mg}, 5 \mathrm{mg}$ or $10 \mathrm{mg}$ at baseline and wk $8^{2}$. Due to a clinical hold on NGF antibodies, $<10 \%$ of pts received the $2^{\text {nd }}$ dose at wk 8 . Pts in the 16-wk Study 2 (NCT02697773), received placebo or tanezumab $2.5 \mathrm{mg}$ at baseline and wk 8 or tanezumab $2.5 \mathrm{mg}$ at baseline and $5 \mathrm{mg}$ at wk $8^{1}$. Pts in the 24-wk Study 3 (NCT02709486), received 
placebo, tanezumab $2.5 \mathrm{mg}$ or $5 \mathrm{mg}$ at baseline, wks 8 and 16. All treatments were given SC. AE data from the treatment period of each study were pooled for placebo, tanezumab $2.5 \mathrm{mg}$ and $5 \mathrm{mg}$ groups and examined by subgroups of gender, age and BMI. Data from the $10 \mathrm{mg}$ group of Study 1 were not included due to the low sample size.

Results: The incidence of any $\mathrm{AE}$ was numerically higher in females across treatment groups and in pts with a BMI $\geq 30 \mathrm{~kg} / \mathrm{m}^{2}$ in the tanezumab $5 \mathrm{mg}$, but not $2.5 \mathrm{mg}$ group, vs the overall population (Table 1 ). SAEs were infrequent but numerically higher across all tanezumab $5 \mathrm{mg}$ subgroups vs placebo (Table 2). Paraesthesia and hypoaesthesia were the most common AEs of APS and were increased in all tanezumab groups in the overall population vs placebo. In any of the subgroups, the incidence of paraesthesia or hypoaesthesia was $\leq 7.8 \%$ and $\leq 3.9 \%$, respectively. The difference within a patient subgroup for paraesthesia or hypoaesthesia was typically comparable with that of the overall population across treatments.

Table 1. Incidence of AEs during the treatment period

\begin{tabular}{lllll}
\hline \% of pts with an $\mathrm{AE}$ in each subgrou & $\begin{array}{c}\text { Placebo } \\
\mathrm{n}=586\end{array}$ & $\begin{array}{c}\text { Tanezumab } \\
2.5 \mathrm{mg} \\
\mathrm{n}=602\end{array}$ & $\begin{array}{c}\text { Tanezumab } \\
2.5 \mathrm{mg} / 5 \mathrm{mg} \mathrm{n}=219\end{array}$ & $\begin{array}{c}\text { Tanezumab } \\
5 \mathrm{mg} \\
\mathrm{n}=347\end{array}$ \\
\hline $\begin{array}{l}\text { Overall population } \\
\text { Gender }\end{array}$ & 51.7 & 52.3 & 47.0 & 54.8 \\
$\quad$ Male & 51.1 & 49.7 & 41.3 & 46.6 \\
$\quad$ Female & 52.0 & 53.6 & 50.4 & 59.0 \\
Age (years) & & & & \\
$\quad<65$ & 55.0 & 54.0 & 44.0 & 54.5 \\
$\geq 65$ & 47.2 & 50.0 & 52.6 & 54.9 \\
BMI $\left(\mathrm{kg} / \mathrm{m}^{2}\right)$ & 58.1 & 46.6 & 51.9 & 45.5 \\
$\quad<25$ & 51.4 & 55.9 & 43.7 & 50.0 \\
$25-<30$ & 49.2 & 51.5 & 43.2 & 58.9 \\
$30-<35$ & 52.7 & 52.3 & 55.3 & 60.9 \\
$\geq 35$ & & & & \\
\hline
\end{tabular}

BMI, body mass index; $\mathrm{kg} / \mathrm{m} 2$, kilogram per square metre

Table 2. Incidence of SAEs during the treatment period

\begin{tabular}{lllll}
\hline \% of pts with a SAE in each subgroup & $\begin{array}{c}\text { Placebo } \\
\mathrm{n}=586\end{array}$ & $\begin{array}{c}\text { Tanezumab } \\
2.5 \mathrm{mg} \\
\mathrm{n}=602\end{array}$ & $\begin{array}{c}\text { Tanezumab } \\
2.5 \mathrm{mg} / 5 \mathrm{mg}=219\end{array}$ & $\begin{array}{c}\text { Tanezumab } \\
5 \mathrm{mg} \\
\mathrm{n}=347\end{array}$ \\
\hline $\begin{array}{l}\text { Overall population } \\
\text { Gender }\end{array}$ & 1.5 & 2.2 & 1.4 & 2.6 \\
$\quad$ Male & 1.6 & 3.0 & 1.3 & 2.5 \\
$\quad$ Female & 1.5 & 1.7 & 1.4 & 2.6 \\
Age (years) & & & & \\
$\quad<65$ & 1.2 & 2.6 & 1.4 & 1.9 \\
$\geq 65$ & 2.0 & 1.6 & 1.3 & 3.1 \\
BMl (kg/m ${ }^{2}$ ) & 1.6 & 1.1 & 0 & 2.3 \\
$\quad<25$ & 1.6 & 2.7 & 0 & 2.7 \\
$25-<30$ & 1.6 & 2.0 & 1.4 & 3.1 \\
$30-<35$ & 1.3 & 2.3 & 4.3 & 1.6 \\
$\geq 35$ & & & & \\
\hline
\end{tabular}

BMI, body mass index; $\mathrm{kg} / \mathrm{m} 2$, kilogram per square metre

Conclusion: This pooled analysis showed that the safety profile of tanezumab in the subgroups studied is broadly similar to that of the overall study population. References:

[1] Schnitzer, T. J. et al. JAMA (2019)

[2] Birbara, C. et al. J Pain Res (2018)

Disclosure of Interests: Francis Berenbaum Grant/research support from: TRB Chemedica (through institution), MSD (through institution), Pfizer (through institution), Consultant of: Novartis, MSD, Pfizer, Lilly, UCB, Abbvie, Roche, Servier, Sanofi-Aventis, Flexion Therapeutics, Expanscience, GSK, Biogen, Nordic, Sandoz, Regeneron, Gilead, Bone Therapeutics, Regulaxis, Peptinov, 4P Pharma, Paid instructor for: Sandoz, Speakers bureau: Novartis, MSD, Pfizer, Lilly, UCB, Abbvie, Roche, Servier, Sanofi-Aventis, Flexion Therapeutics, Expanscience, GSK, Biogen, Nordic, Sandoz, Regeneron, Gilead, Sandoz, Alan Kivitz Shareholder of: AbbVie, Amgen, Gilead, GSK, Pfizer Inc, Sanofi, Consultant of: AbbVie, Boehringer Ingelheim,,Flexion, Genzyme, Gilead, Janssen, Novartis, Pfizer Inc, Regeneron, Sanofi, SUN Pharma Advanced Research, UCB, Paid instructor for: Celgene, Genzyme, Horizon, Merck, Novartis, Pfizer, Regeneron, Sanofi, Speakers bureau: AbbVie, Celgene, Flexion, Genzyme, Horizon, Merck, Novartis, Pfizer Inc, Regeneron, Sanofi, Thomas Schnitzer Consultant of: Pfizer, Lilly, AstraZeneca, GSK, Mark Brown Shareholder of: Pfizer Inc, Employee of: Pfizer Inc, Sean Donevan Shareholder of: Pfizer Inc., Employee of: Pfizer Inc., Anne Hickman Shareholder of: Pfizer Inc, Employee of: Pfizer Inc, Lars Viktrup
Shareholder of: Eli Lilly and Company, Employee of: Eli Lilly and Company, Christine West Shareholder of: Pfizer Inc, Employee of: Pfizer Inc, Takaharu Yamabe Shareholder of: Pfizer, Employee of: Pfizer

DOI: 10.1136/annrheumdis-2020-eular.3701

\section{FRI0393 BASELINE CHARACTERISTICS OF THE STUDY POPULATION IN ROCCELLA, A PHASE 2 CLINICAL TRIAL EVALUATING THE EFFICACY AND THE SAFETY OF S201086/GLPG1972 IN PATIENTS WITH KNEE OSTEOARTHRITIS}

K. Bernard ${ }^{1}$, S. Grankov ${ }^{1}$, M. Van der Stoep ${ }^{2}$, A. Lalande ${ }^{1}$, O. Imbert ${ }^{1}$,

D. Phung ${ }^{2}$, D. Chimits ${ }^{1}$, K. Muller ${ }^{2}$, E. Van der Aar ${ }^{2}$, H. Deckx ${ }^{2}$, M. Pueyo ${ }^{1}$,

F. Eckstein ${ }^{3,4} .{ }^{1}$ Institut de Recherches Internationales Servier, SURESNES,

France; ${ }^{2}$ Galapagos, Mechelen, Belgium; ${ }^{3}$ Institute of Anatomy \& Cell Biology,

Paracelsus Medical University, Salzburg, Austria; ${ }^{4}$ Chondrometrics Gmbh,

Ainring, Germany

Background: Osteoarthritis $(O A)$ is a degenerative joint disease involving structural pathology of all joint tissues, and most commonly affecting the knee, hip and hand. Degradation of the cartilage extracellular matrix represents a central feature of $O A$ and is widely thought to be mediated by proteinases that degrade primarily aggrecan and collagen. ADAMTS-5, a Disintegrin And Metalloproteinase with ThromboSpondin-motif-5, is a key aggrecan-cleaving enzyme involved in cartilage degradation. S201086/GLPG1972, a potent and highly selective inhibitor of ADAMTS-5, is an oral Disease-Modifying OsteoArthritis Drug (DMOAD) candidate.

Objectives: The primary objective of the ROCCELLA phase 2 clinical trial (NCT03595618) is to evaluate the effect of S201086/GLPG1972 over 52 weeks of treatment ( 3 dose groups compared to placebo) in reducing cartilage loss. Cartilage thickness of the knee is being measured quantitatively by Magnetic Resonance Imaging. Here, we describe the baseline characteristics of patients included in the ROCCELLA clinical trial.

Methods: The main inclusion criteria were: male or female, aged 40 to 75 , with a diagnosis of knee OA according to the clinical and radiological criteria of the American College of Rheumatology. The target knee had to meet a pain score between 40 and $90 \mathrm{~mm}$ on a $100 \mathrm{~mm}$ Visual Analog Scale (VAS), and the following radiographic feature upon central radiographic readings: Kellgren/Lawrence (KL) 2 or 3 and OARSI medial joint space narrowing (JSN) 1 or 2 (for more details see Deckx et al. OARSI 2020). The rationale for these specific radiographic inclusion criteria was to ensure sufficient cartilage loss over 12 months to assess the efficacy of S201086/GLPG1972.

Results: Across 12 countries, 3319 patients were screened and 932 were finally included in the study. The screen failure of $72 \%$ is mainly due to the radiological criteria. The age of the patients was $62.9 \pm 7.3$ years (mean \pm SD) with a majority of women $(69.3 \%)$. The BMI was $30.5 \pm 4.7 \mathrm{~kg} / \mathrm{m}^{2}$. The duration of knee OA was $7.2 \pm 6.9$ years. Five hundred and one $(53.8 \%)$ patients reported a medical history of musculoskeletal and connective tissue disorders, mainly osteoarthritis in other sites $(20.2 \%)$, back pain (13.6\%), and arthralgia (9.8\%). At inclusion, $97.2 \%$ of the patients were taking different types of drug treatments, mainly anti-inflammatory and anti-rheumatic products $(69.4 \%)$ and analgesics (42\%). At baseline, $11 \%$ of the target knees were $\mathrm{KL} 2$ and $89 \%$ were $\mathrm{KL} 3 ; 32 \%$ were OARSI medial JSN grade 1 and $68 \%$ grade 2 . Target knees at inclusion had a pain score on the VAS of $63.5 \pm 11.4 \mathrm{~mm}$ (range $0-100$, with 0 for no and 100 for extreme pain) and a total WOMAC (Likert 3.1) score of $48.0 \pm 15.0$ (range 0-96). The WOMAC subscores for pain, stiffness and physical function were $10.0 \pm 3.2$ (range 0-20), $4.2 \pm 1.6$ (range $0-8$ ) and $33.8 \pm 11.2$ (range $0-68$, indicating functional limitation), respectively.

Conclusion: For this clinical trial, patients were selected to present radiological criteria (i.e. OARSI JSN 1 and 2) to ensure sufficient structural progression (cartilage loss) over 12 months, as well as clinical symptoms. These stringent selection criteria were the main cause for the high screen failure rate. These baseline characteristics should warrant the ability to evaluate the efficacy of S201086/ GLPG1972 as a DMOAD candidate. The search for an effective pharmacological treatment that can prevent or cure OA remains a major challenge and unmet medical need.

Disclosure of Interests: Katy Bernard Employee of: Institut de Recherches Internationales Servier, Sergey GRANKOV Employee of: Institut de Recherches Internationales Servier, Marjolijne van der Stoep Employee of: Galapagos, Agnès Lalande Employee of: Institut de Recherches Internationales Servier, Olivier Imbert Employee of: Institut de Recherches Internationales Servier, De Phung Employee of: Galapagos, Damien Chimits Employee of: Institut de Recherches Internationales Servier, Karine Muller Employee of: Galapagos, Ellen van der Aar Employee of: Galapagos, Henri Deckx Employee of: Galapagos, Maria Pueyo Employee of: Institut de Recherches Internationales Servier, Felix Eckstein 